\title{
Are evoked potentials clinically useful in the study of patients with Chiari malformation Type 1?
}

\author{
Dulce Moncho, MD, ${ }^{1,3}$ Maria A. Poca, MD, PhD, ${ }^{2,3}$ Teresa Minoves, MD, ${ }^{1}$ Alejandro Ferré, MD, ${ }^{1,3}$ \\ Victoria Cañas, MSc, ${ }^{3}$ and Juan Sahuquillo, MD, PhD ${ }^{2,3}$
}

${ }^{1}$ Clinical Neurophysiology Department, ${ }^{2}$ Neurosurgical Department, and ${ }^{3}$ Neurotraumatology and Neurosurgery Research Unit (UNINN), Vall d'Hebron University Hospital, Vall d'Hebron Research Institute, Universitat Autònoma de Barcelona, Spain

\begin{abstract}
OBJECTIVE In this study, the authors describe the brainstem auditory evoked potential (BAEP) and somatosensory evoked potential (SSEP) alterations found in a large cohort of patients with Chiari malformation Type 1 (CM-1), the relationship between the BAEPs/SSEPs and the clinical findings, the abnormalities in patients with associated syringomyelia, and the clinical and neuroradiological risk factors that are associated with abnormal evoked potentials (EPs).

METHODS A prospectively collected database containing 545 patients with $\mathrm{CM}-1$ was queried to search for patients satisfying the following criteria: 1) an age of at least 14 years, 2) neuroradiological criteria of CM-1,3) no prior Chiarirelated surgeries, and 4) preoperative EP studies conducted at the authors' institution. The 200 patients included in this cohort were classified into CM-0, CM-1, and CM-1.5 subtypes. Linear, planimetric, and angular measurements of the posterior fossa were conducted, as well as syringomyelia measurements. Two separate multiple logistic regression models were used, one to predict the covariates associated with abnormal BAEPs, and a second model to explore the variables associated with an abnormal SSEP. In these models, the BAEPs and SSEPs were dichotomized as being normal or abnormal.
\end{abstract}

RESULTS Headaches were the main symptom in $70.5 \%$ of the patients, and Valsalva-induced headaches were most frequent in patients with $\mathrm{CM}-1$ and $\mathrm{CM}-1.5$ compared with patients with $\mathrm{CM}-0(p=0.031)$. BAEPs were abnormal in $38.5 \%$ of patients, and abnormal SSEPs were found in $43.5 \%$ of the entire cohort. Syringomyelia was most frequent in patients with CM-0 (64.3\%) and CM-1 (51.1\%) compared with those with CM-1.5 (34.7\%; $p=0.03)$. Age (OR 1.03, 95\% $\mathrm{Cl} 1.00-1.06)$, the degree of tonsillar herniation (OR 1.08, 95\% Cl 1.01-1.16), and lower cranial nerve dysfunction (OR $3.99,95 \% \mathrm{Cl} 1.29-14.01)$ had a statistically significant correlation with abnormal BAEPs. Only age (OR $1.07,95 \% \mathrm{Cl}$ 1.04-1.10) and the degree of tonsillar herniation (OR 1.11, 95\% Cl 1.04-1.19) had a statistically significant correlation with abnormal SSEPs.

CONCLUSIONS A high percentage of patients with CM-1 exhibited EP alterations regardless of their clinical or radiological findings. These findings suggest that EPs do not add any clinically relevant information nor are they helpful in establishing which symptomatic patients with CM should undergo surgical treatment. However, BAEP and SSEP studies clearly play an important role in incidentally detected patients with $\mathrm{CM}$ and may help to establish objective evidence of subclinical dysfunctions. In addition, neurophysiological studies may help to define subgroups of patients who require further testing and follow-up to personalize strategies for the management of incidental and oligosymptomatic patients. http://thejns.org/doi/abs/10.3171/2015.11.JNS151764

KEY WORDS Chiari malformation; brainstem auditory evoked potential; somatosensory evoked potential; syringomyelia; diagnostic and operative techniques

ABBREVIATIONS AP = anteroposterior; $\mathrm{BAEP}=$ brainstem auditory evoked potential; $\mathrm{CM}=\mathrm{Chiari}$ malformation; $\mathrm{CM}-0=\mathrm{CM}$ Type $0 ; \mathrm{CM}-1=\mathrm{CM}$ Type $1 ; \mathrm{CM}-1.5=\mathrm{CM}$ Type 1.5; CVJ = craniovertebral junction; EP = evoked potential; FM = foramen magnum; IPL = interpeak latency; MN = median nerve; PF = posterior fossa; PFR = PF reconstruction; PTN = posterior tibial nerve; SCR = syringo-cord ratio; SSEP = somatosensory evoked potential; VB = vertebral body.

ACCOMPANYING EDITORIAL See pp 600-605. DOI: 10.3171/2015.12.JNS152624.

SUBMITTED July 28, 2015. ACCEPTED November 12, 2015.

INCLUDE WHEN CITING Published online April 15, 2016; DOI: 10.3171/2015.11.JNS151764. 
$\mathrm{T}$

HE term Chiari malformation (CM) defines a group of neurodevelopmental disorders that share a variable hindbrain herniation below the foramen magnum (FM). Despite the fact that more than a century has passed since the original description of $\mathrm{CM}$ by the Austrian pathologist Hans Chiari in 1891, ${ }^{11-13}$ the terminology of CM remains a source of considerable debate and confusion. Due to the secondary role that Arnold played in the original description, "Chiari malformation" is the most widely accepted eponym..$^{33}$

The diagnosis and treatment of CM has been strongly influenced by the neuroradiological criteria used for its diagnosis; its classification continues to be based on the original description of CM having 4 types. ${ }^{11-13} \mathrm{CM}$ Type 1 (CM-1) is defined as a variable descent of 1 or both cerebellar tonsils below the FM. Because most patients are referred for MRI in the workup for recurrent headaches, the initial detection is made by neuroradiologists who may use different tonsillar herniation cutoffs -3 and $5 \mathrm{~mm}$ are the most commonly used-for making a diagnosis. ${ }^{4,6,7,27,29,38,41}$ These variable cutoffs result from several MRI studies that have analyzed the relative position of the cerebellar tonsils in healthy volunteers, patients with unrelated CM complaints, and symptomatic CM patients. Barkovich et al. had a dominant influence on defining CM-1 as a tonsillar herniation below the FM that was more than $3 \mathrm{~mm}$ measured on a T1-weighted midsagittal MR image. ${ }^{4}$ However, different studies have shown that the degree of tonsillar herniation is not related to the severity of the symptoms and that syringomyelia, a finding that affects $30 \%-65 \%$ of patients with CM-1, ${ }^{7,28}$ is frequently observed in patients with minimal or no tonsillar herniation but with a crowded posterior fossa (PF) ${ }^{6}$

It is accepted that classic CM-1 is a congenital disease characterized by autosomic dominant transmission. ${ }^{43}$ The most frequent finding is a hypoplasia of the PF that induces a variable descent of the hindbrain below the FM. CM-1 has been a contentious subject in the last two decades because of the wide availability of MRI and its frequent incidental diagnosis both in adult and pediatric populations. Many patients are diagnosed incidentally or in very early stages of the disease; other patients are referred to a neurologist or neurosurgeon because of overt symptomatology or the existence of a spinal cord syrinx. One of the most controversial issues clinicians face is whether surgery is necessary in patients who are oligosymptomatic or asymptomatic and present with moderate to severe tonsillar herniation. Many of these patients present with significant alterations in sleep, a pattern of severe sleep apnea-hypopnea syndromes, and even respiratory failure.,16 A second group to be concerned about is oligosymptomatic/asymptomatic patients with an incidentally detected syrinx. In this group, the degree of tonsillar herniation is a poor predictor of whether these patients will experience clinical progression and if the risk-to-benefit ratio of surgery is acceptable compared with the natural evolution of the disease.

The increased availability of high-field MRI has enabled detailed studies of many patients with CM-1. These studies have revealed that the traditional neuroradiological criteria do not correlate well with the more severe symp- toms that patients with $\mathrm{CM}$ present with, such as syringomyelic syndrome and/or sleep apnea. ${ }^{6,7}$ In 1998, Iskandar et al. presented 5 pediatric patients with significant syringomyelia, a crowded $\mathrm{PF}$, and no tonsillar herniation. ${ }^{19}$ Some authors have used the term Chiari Type $0(\mathrm{CM}-0)$ to define this syndrome characterized by a reduced or absent cisterna magna as a surrogate measure of PF overcrowding. ${ }^{6,23,26,39}$ In addition, Tubbs et al. introduced the term CM Type-1.5 (CM-1.5) in 2004 to describe a subgroup of patients with CM-1 who, in addition to tonsillar herniation, also presented with caudal descent of the brainstem below the FM. ${ }^{41}$

In the CM workup, brainstem auditory evoked potentials (BAEPs) and somatosensory evoked potentials (SSEPs) are useful but neglected methods to assist in decision-making. Evoked potential (EP) studies are not routinely conducted in these patients and their predictive values remain unknown. A few studies have described the findings of EP recordings in terms of their role in the diagnosis and follow-up of CM-1. However, with the exception of our preliminary report published elsewhere, ${ }^{31}$ all studies to date have included fewer than 28 patients $^{32}$ and only 1 report conducted both BAEP and SSEP recordings in a single pediatric patient. ${ }^{45} \mathrm{It}$ is therefore quite clear that further studies with larger cohorts are needed. The purpose of this study was to describe the BAEP and SSEP alterations found in a large cohort of patients with classic CM-1 without significant ventral compression of the brainstem or basilar invagination, as well as their relationship to the clinical findings, their frequency in the different subtypes of CM (CM-0, CM-1, and CM-1.5), and the abnormalities in patients with associated syringomyelia. A second goal was to determine the risk factors that were associated with normal/abnormal EPs. Knowledge of these factors can help to define a subgroup of patients who require further testing and closer follow-up. In addition, identifiable risk factors may be useful for developing personalized strategies for the management and follow-up of incidentally detected and oligosymptomatic patients.

\section{Methods}

All data were obtained at our institution, a large tertiary care setting with a referral pattern for $\mathrm{CM}$ and other congenital anomalies of the craniovertebral junction (CVJ) in both adults and children. In 2007, a research database was established to register all patients admitted to the Department of Neurosurgery of the Vall d'Hebron University Hospital for study or surgical treatment of these conditions. Data from patients treated from 1989 to 2005 were entered into the database retrospectively, and patients have been prospectively included since 2006 . In this database, a core data set of clinical data and neuroradiological, neurophysiological, follow-up, and outcome measures was recorded by the 2 authors in charge of surgical treatment (M.A.P. and J.S.). Additional MRI measurements were performed retrospectively. The routine study protocol in this period was modified slightly but always included a structured anamnesis and neurological examination, cranial and spinal MRI, and CT scan of the CVJ with coronal, sagittal, and 3D reconstructions. In 1998, BAEPs and SSEPs were in- 
troduced into the routine workup, and whole-night polysomnography for the detection of covert sleep disorders was incorporated into the protocol in 2006..$^{16}$ In surgical candidates, a CT angiogram is also routinely conducted to detect arterial and venous abnormalities of the CVJ.

\section{Study Population}

A database containing 547 patients was queried to search for patients admitted from January 1, 2006, to December 31, 2014. Inclusion criteria were the following: 1) patients over 14 years old; 2) neuroradiological criteria of $\mathrm{CM}-1$; 3) no prior Chiari-related surgery; and 4) preoperative EP studies (BAEPs and SSEPs) conducted at the Department of Neurophysiology of our institution. CM-1 was diagnosed in cases of tonsillar herniation of at least 3 $\mathrm{mm}$ below the FM plane (basion-opisthion line; subtypes CM-1 and CM-1.5) or when patients had an absent cisterna magna, tonsillar herniation less than $3 \mathrm{~mm}$, and/or associated syringomyelia (subtype CM-0).

We excluded all patients who presented with hindbrain herniation as a part of what we define as complex CVJ malformations. The complex CVJ malformation usually presents with tonsillar herniation and at least 3 of the following abnormalities: significant retroflexed odontoid, basilar invagination, platybasia, severe bone abnormalities in the $\mathrm{C} 0-\mathrm{C} 2$ complex, uni-or bilateral occipital condyle hypoplasia, atlantooccipital assimilation, and/or other abnormalities that condition an anterior compression of the cervicomedullary junction. All patients with CM-1 and concomitant diseases that may alter EP recordings-including deafness since childhood, severe neuropathy or other associated CNS diseases such as demyelinating disease, tumors, etc.- -were also excluded. The study received institutional review board approval.

\section{Classification}

Although most patients included in our cohort could be considered to have classic CM-1, for the purposes of this study we divided the entire cohort into the categories suggested by Tubbs et al. ${ }^{40}$ In this classification (CM-0, CM-1, and CM-1.5) we introduced a minor modification in the threshold used to separate CM-0 from CM-1. We used the cutoff of $3 \mathrm{~mm}$ and not the $5 \mathrm{~mm}$ proposed by Tubbs et al. ${ }^{40}$ The rationale for this modification is explained in the discussion. Examples of the 3 types of patients are shown in Fig. 1.

\section{Morphometric Parameters in Neuroimaging Studies}

All patients underwent complete neuroradiological studies available directly from our Picture Archiving and Communication System. These were in DICOM format or in digitalized format of original nondigital MR images. For all morphometric analysis, representative images of the MRI were exported to a compatible image file format (TIFF, JPEG, or PNG) and analyzed using the public domain ImageJ software (version 1.43, NIH; http://rsb.info. nih.gov/ij). From the digitalized images, the following craniometric parameters were evaluated and are summarized in Fig. 1.

\section{Linear and Planimetric Parameters}

A number of linear and planimetric parameters were evaluated. The Evans index was defined as the maximal ventricular distance between both frontal horns at the level of the foramen of Monro divided by the maximum transverse inner diameter of the skull in the same CT scan slice. ${ }^{15}$ The FM anteroposterior (AP) diameter, the greatest sagittal diameter of the FM, was measured as the basionopisthion distance rounded to the nearest millimeter on a sagittal midline T1-weighted MR image. Tonsillar herniation was measured in a manner similar to that used in other studies on a sagittal midline T1-weighted MR image. ${ }^{4,27}$ Briefly, a line connecting the basion and opisthion was drawn to define the plane of the FM. Tonsillar herniation was then quantified by extending a line perpendicular from the basion-opisthion line to the most caudal part of the tonsils (Fig. 1). The tonsillar position above the FM was assigned a negative value.

Clivus length was the distance between the top of the dorsum sellae and the basion (in the same sagittal MRI slice in which tonsillar herniation was evaluated). The odontoid tip-Chamberlain's line distance was defined as the distance in millimeters from the tip of the odontoid above or below Chamberlain's line (the line drawn from the posterior hard palate to the tip of the opisthion) on the midsagittal midline T1-weighted MR image. Finally, the sagittal PF area was determined. As previously described by Urbizu et al.,42 the MRI midsagittal slice was used to calculate the area of the PF in the midline. A polygon was drawn with the following boundaries: the full length of the tentorium until its insertion in the occipital bone, a line following the inner cortical margin of the occipital bone from the insertion of the tentorium into the opisthion, the opisthion-basion line, the clivus from the basion to the dorsum sellae, and a final line extending from the latter point to the most anterosuperior part of the tentorium (Fig. 1).

\section{Angular Measurements}

As previously described ${ }^{43}$ and also shown in Fig. 1, 3 angular measurements were obtained: the tentoriumoccipital bone angle, the basal angle, and Wackenheim's (or the clivus-canal) angle. The tentorium-occipital bone angle was measured as the angle formed by the tentorium and supraocciput. ${ }^{9}$ The basal angle was defined as the angle formed by a line extending from the nasion to the top of the dorsum sellae; a second line was drawn from the dorsum sellae to the basion..$^{22}$ Wackenheim's angle, or the clivus-canal angle, was measured on a midsagittal T1weighted MRI slice; it was defined as the angle formed by a line extending along the posterior surface of the clivus extended to the most superodorsal part of the dens and then downward to the most inferodorsal portion of the $\mathrm{C}-2$ vertebral body $(\mathrm{VB}){ }^{8}$

\section{Syringomyelia Measurements}

In patients with syringomyelia, a number of measurements (Fig. 1) were conducted. Extension of the syrinx was defined as the number of VBs between the superior and the inferior limit of the cavity. The maximum AP diameter of the syrinx at its widest level was measured on 

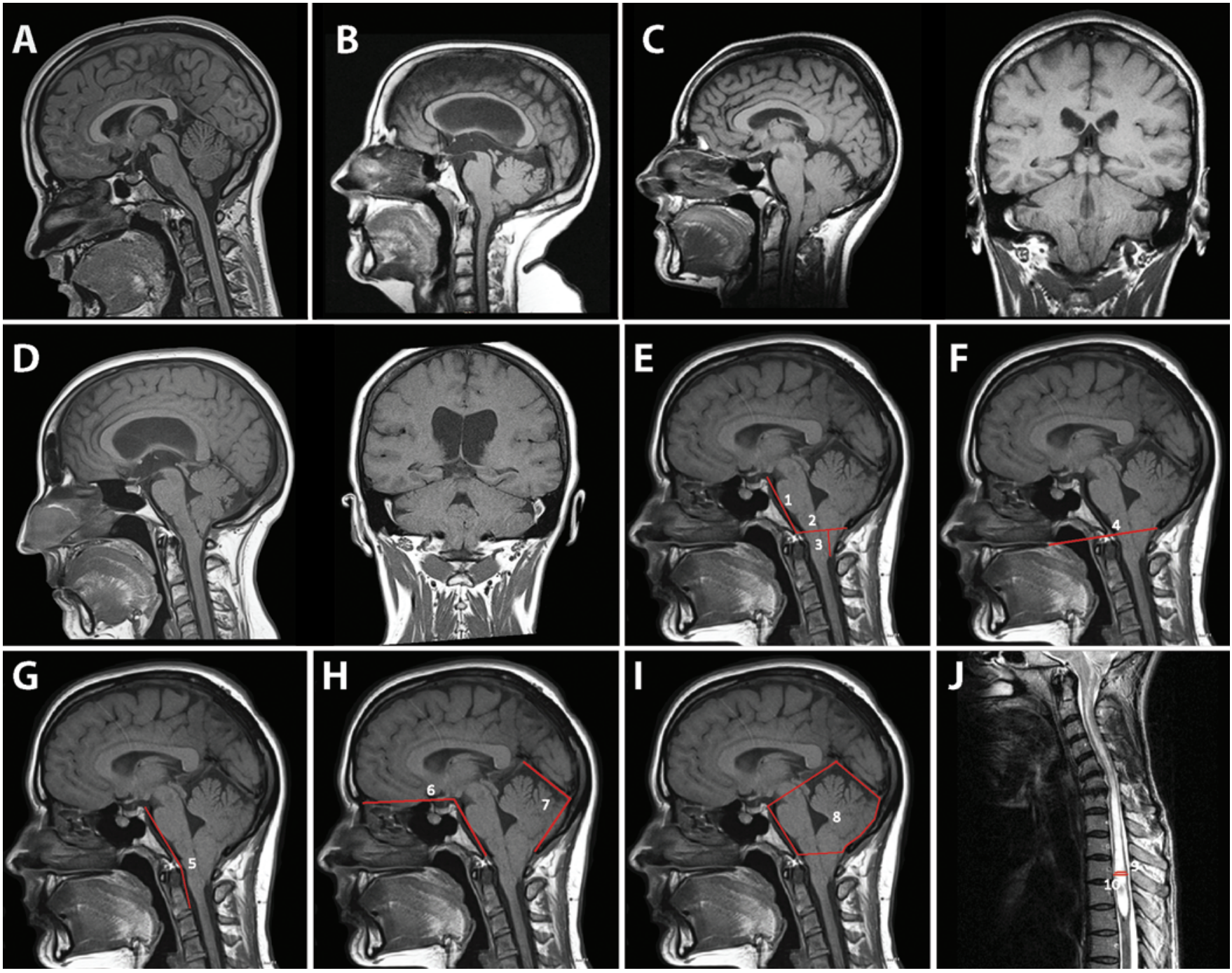

FIG. 1. Examples of the 3 types of CMs and morphometric measurements of the different anatomical structures of the PF and the CVJ. A: Midsagittal-T1 weighted image of a 19-year-old woman with headaches suggestive of migraine, who was used as a control. Cerebellar tonsils are well above the FM and the cisterna magna is opened. B: CM-0. Image from a 54-year-old woman admitted because of a 6-month history of dysphagia. In this sagittal MR image, a ventricular dilation is observed, together with a tonsillar herniation of $3 \mathrm{~mm}$. C: CM-1. Images from a 34-year-old woman with a 5-year medical history of straining-induced occipital headaches and dizziness and subjective weakness in the left arm. Midsagittal (left) and coronal (right) T1-weighted images show severe bilateral tonsillar herniation reaching C-2 and associated cervical cord syringomyelia. D: CM-1.5. Images from a 52-year-old woman with insidious symptoms in the last 3 years of cough-induced occipital headache, dizziness, and difficulty swallowing solid foods. Midsagittal (left) and coronal (right) T1-weighted images show hydrocephalus (Evans index 0.36), a bilateral symmetric 8-mm tonsil descent of both cerebellar tonsils below the FM, and an obex (left) well below the FM plane. E: Image showing the clivus length (1), opisthion-basion line (2), and line measuring the descent ( $\mathrm{mm}$ ) of the cerebellar tonsils below the FM (3). F: Example of Chamberlain's line (4), or the line drawn from the posterior hard palate to the tip of the opisthion on the midsagittal midline T1-weighted MR image. G: MR image demonstrating Wackenheim's angle (5), or clivus-canal angle. H: The basal angle (6) is the angle formed by a line extending from the nasion to the top of the dorsum sellae and a second line from the dorsum sellae to the basion. The tentorium-occipital bone angle (7) is the angle formed by the line following the tentorium and the supraocciput. I: The sagittal PF area (8) is calculated in the MRI midsagittal slice as a polygon drawn with the following boundaries: the full length of the tentorium until its insertion in the occipital bone, a line following the inner cortical margin of the occipital bone from the insertion of the tentorium into the opisthion, the opisthion-basion line, the clivus from the basion to the dorsum sellae, and a final line extending from the latter point to the most anterosuperior part of the tentorium. J: Cervicodorsal syringomyelia (9) is the maximum AP diameter of the syrinx at its widest level. The spinal cord diameter (10) is the maximum AP diameter of the spinal cord at the same level in which the maximum diameter of the syrinx was measured. Figure is available in color online only. 
the midsagittal MRI slice. The spinal cord diameter was defined as the maximum AP diameter of the spinal cord at the same level in which the maximum AP diameter of the syrinx was measured. The syringo-cord ratio (SCR) was used in a previous paper ${ }^{37}$ and is calculated by dividing (at the widest level of the syrinx) the maximum AP distance of the syrinx by the AP of the spinal cord at the same level. The SCR $(\%)=$ AP diameter of the syrinx/AP diameter of spinal cord $\times 100$.

\section{Definitions}

Hydrocephalus was defined as an Evans index greater than $0.30,,^{15}$ and basilar invagination was defined according to the criteria of Batista et al., i.e., when the tip of the odontoid was at least $3 \mathrm{~mm}$ above Chamberlain's line. ${ }^{5}$

\section{Brainstem Auditory Evoked and Somatosensory Evoked Potentials}

Methods described below have been described in detail elsewhere. ${ }^{31}$ In summary, BAEPs and SSEPs in patients with CM-1 were recorded using a Nicolet VikingIV EMG/EP unit (Nicolet) following the guidelines of the American Electroencephalographic Society, ${ }^{1}$ the "Recommendations for the clinical use of somatosensory-evoked potentials," 14 and the "IFCN recommended standards for short latency somatosensory evoked potentials." ${ }^{4}$ To obtain normative data, we used a second device, the Viking Select (Viasys Healthcare), acquired in 2010. The comparative study between EP values obtained in patients with CM-1 and those of the normal control group was conducted after demonstrating the reproducibility of both devices. ${ }^{30}$ The normal range was established from 50 healthy volunteers who were age-, sex-, and height-matched controls (19 men and 31 women, mean age $40.2 \pm 12.6$ years, mean height $166.1 \pm 8.3 \mathrm{~cm}$ ), a cohort that was described elsewhere. ${ }^{31}$

BAEPs were considered abnormal when any of the following criteria was met: 1) absence of wave I, III, and/or $\mathrm{V}$; 2) when the latency of waves I, III, and V and/or interpeak latencies (IPLs) I-III, III-V, and I-V exceeded the upper range of normality $(1.83 \mathrm{msec}$ for wave I, $4.04 \mathrm{msec}$ for wave III, $6.12 \mathrm{msec}$ for wave V, $2.51 \mathrm{msec}$ for I-III IPL, $2.35 \mathrm{msec}$ for III-V IPL, and $4.62 \mathrm{msec}$ for I-V IPL); 3) asymmetry between both ears: the interside latencies and IPL differences were considered asymmetrical when they were greater than $0.30 \mathrm{msec} ; 4)$ when the wave $\mathrm{V}$ or IV-V complex had a significantly smaller amplitude than wave I (V/I and IV/I amplitude ratio were both lower than $0.5)$, especially when accompanied by abnormalities in latency. To classify posterior tibial nerve (PTN) SSEPs as abnormal the following criteria were used: 1) absence of the N8, N22, N28, and/or P37 waves, whereas the isolated absence of waves N22 and/or N28 was not considered abnormal; 2) when N22-P37 IPL exceeded $21.13 \mathrm{msec}$; 3) when P37/N45 amplitude was lower than $0.580 \mu \mathrm{V}$; a mild decrease $(<10 \%)$ in amplitude as an isolated finding was considered normal; 4) interside asymmetry: N22-P37 IPL was considered asymmetrical when the interside difference was greater than $2.6 \mathrm{msec}$, whereas the interside amplitude difference was considered abnormal when the difference was greater than 50\% for P37/N45 amplitude.
For median nerve (MN) SSEPs the abnormal criteria were: 1) absence of waves N9, N13, and/or N20; 2) when N13-N20 IPL exceeded the upper limit of $6.82 \mathrm{msec}$ and/ or N9-N13 IPL exceeded the upper limit of $4.57 \mathrm{msec}$; 3 ) when N13 amplitude was lower than $1.2 \mu \mathrm{V}$ and/or N20 amplitude was lower than $1.77 \mu \mathrm{V}$, but slight decreases $(<$ $10 \%$ ) in amplitude as a single finding was not considered pathological; 4) interside asymmetry: N9-N13 and N13N20 IPLs were considered asymmetrical when interside differences were greater than $1.4 \mathrm{msec}$. Interside amplitude difference was considered pathological when the difference was greater than $50 \%$ for N9, N13, and N20 waves. When either PTN SSEPs or MN SSEPs were abnormal, SSEPs were considered as abnormal.

\section{Statistical Analysis}

Descriptive statistics were obtained for each variable. For continuous variables, summary statistics were the mean, median, range, and standard deviation. Percentages and sample sizes were used to summarize categorical variables. The Shapiro-Wilk test and inverse probability plot were used to test whether data followed a normal distribution. To correlate two continuous variables, the most conservative Kendall's tau (when data did not follow a normal distribution) or Pearson correlation test (for data following a normal distribution) was used. Statistical analyses were performed using R (version 3.2.0, R Foundation for Statistical Computing; http://www.R-project.org) and the integrated development environment R Studio (version 0.99.441, RStudio Inc.; http://www.rstudio.com).

We used multiple logistic regression to explore associations between 1 dichotomous outcome variable with multiple exposure continuous, ordinal, or categorical variables. The purpose of multiple logistic regression in this study was to isolate the relationship between the predictors and the outcome variable from the effects of covariates. We used two separate multiple logistic regression models, one to predict the covariates associated with abnormal BAEPs and a second to explore variables associated with an abnormal SSEP. In this model the BAEPs and SSEPs were assigned the dichotomic values 0 (normal) or 1 (abnormal). To conduct this analysis we applied the General Linear Model function in R ( $\mathrm{glm}$ ) by using the binomial family. The preselected input variables were introduced in the model according to the method suggested by Hosmer et al ${ }^{18}$ In brief, risk factors in a continuous scale for abnormal BAEPs and SSEPs were, in a first step, separately tested in a univariate logistic regression analysis. Categorical variables were tested for significance via a standard contingency table analysis of the outcome $(y=0,1)$ versus the $\mathrm{k}$ levels of the independent variable. ${ }^{18}$ Significance was tested with the Pearson chi-square test. Independent predictors for BAEPs were age and all morphometric and planimetric parameters except for Evans index and the syringomyelia measurements. For SSEPs, all the planimetric measurements except the Evans index were entered. All variables that were significant in the univariate analysis were then tested by forward multiple logistic regression analysis. For the univariate analysis we considered variables significant when $\mathrm{p}<0.25 .^{18}$ Variables that were not statistically significant were eliminated and a new model 
was generated without them. In the variables of interest, the original coefficients, their statistical significance, the 95\% confidence intervals, and the odds ratio (OR) were reported. A 2 -tailed $p$ value $<0.05$ was considered statistically significant for the multiple logistic regression.

\section{Results}

Of the 220 patients initially selected, 20 were excluded. The reasons for exclusion were the presence of a complex CVJ malformation (14 patients), congenital deafness (1 patient), severe diabetic neuropathy (1 patient), Guillain-Barré sequelae (1 patient), vestibular schwannoma (1 patient), cerebellopontine angle epidermoid cyst (1 patient), and brainstem dysgenesis (1 patient). The final cohort consisted of 200 patients: 58 men (29\%) and 142 women (71\%), with a mean age $( \pm$ SD) of $41.9 \pm 13.4$ years (range $15-70$ years). One hundred and four patients (52\%) underwent PF surgery. All patients with CM-0/CM-1 were treated using an extraarachnoidal technique called "PF reconstruction" (PFR) first described by our group in 1994. ${ }^{36,37}$ In some patients with CM-1 and in most patients with CM-1.5, PFR was performed in association with an intraarachnoid exploration, limited coagulation and/or subpial resection of the tonsils, and exploration of the foramen of Magendie.

According to the described criteria, 14 patients $(7.0 \%)$ were included in the CM-0 group, 137 (68.5\%) in the CM-1 group, and $49(24.5 \%)$ in the CM-1.5 group. A summary of the clinical findings and associated pathology is presented in Table 1. No significant differences in age were found among the 3 groups. Syringomyelia was most frequent in CM-0 (64.3\%) and CM-1 (51.1\%) compared with CM-1.5 $\left(34.7 \% ; \chi^{2}=4.604, \mathrm{p}=0.03\right)$.

\section{Clinical Symptoms and Signs}

Headaches were the main symptom in $70.5 \%$ of the patients, and headache that was exacerbated with Valsalva maneuvers was most frequent in patients with CM-1 and CM-1.5 compared with CM-0 $\left(\chi^{2}=3.95, \mathrm{p}=0.031\right)$. Other common symptoms included dizziness, subjective sensory loss, anxiety and dysphagia (Table 1). Neurological examination was abnormal in $54.5 \%$ of the patients, including those with CM-0. Most neurological abnormalities (thermalgesic disturbances, motor deficits, etc.), except for nystagmus and lower cranial nerves palsies, were related to the presence of syringomyelia.

\section{Neuroimaging Studies}

In the 96 patients with syringomyelia, the syrinx affected the cervical spinal cord in 91 cases $(94.8 \%)$ and was limited to the dorsal spinal cord in only 5 patients (5.2\%). The median SCR was 57.1\% (range 12.5\%-93.3\%). The summary of the linear and planimetric parameters, angular measurements, and syringomyelia measurements are summarized in Table 2. No significant differences between CM subtypes 0,1 , and 1.5 were found except for tonsillar herniation (ANOVA on ranks: $\mathrm{H}=62.685, \mathrm{p}<$ 0.001; Dunn's method: CM-1.5 vs CM-0, $\mathrm{p}<0.05$; CM-1.5 vs CM-1, p < 0.05; CM-1 vs CM-0, p < 0.05) and Wackenheim's angle (ANOVA: differences between CM-0 and CM-1.5, $\mathrm{p}=0.004$; between CM-1 and CM-1.5, $\mathrm{p}=$
0.006, and CM-0 and CM-1, p = 0.05). The entire cohort presented significant differences in some morphometric measurements when compared with a control group of 50 patients who underwent brain MRI after presenting with a clinically isolated syndrome suggestive of multiple sclerosis that we published elsewhere. ${ }^{42}$ In summary, our cohort presented radiological signs of an underdeveloped PF with a significantly shorter clivus length (mean $40.5 \pm 4.4$ vs $47.0 \pm 3.3 \mathrm{~mm}$ in controls, $\mathrm{p}<0.0001)$, reduced sagittal $\mathrm{PF}$ area (mean $31.9 \pm 3.8$ vs $37.8 \pm 3.5 \mathrm{~cm}^{2}$ in controls, $\mathrm{p}<$ $0.0001)$ and a more acute tentorium-occipital bone angle (mean $90.2 \pm 9.2$ vs $93.2 \pm 7.1^{\circ}$ in controls, $\mathrm{p}=0.032$ ). The AP diameter of the FM was similar in both CM patients and controls (mean $35.9 \pm 3.1$ vs $35.4 \pm 3.0 \mathrm{~mm}$ in controls, $\mathrm{p}=0.305)$.

\section{Evoked Potentials}

Eighty patients (40\%) showed both normal BAEPs and SSEPs. Of the 120 patients with altered EPs, 44 patients (22\%) showed abnormalities in both BAEPs and SSEPs, 43 patients $(21.5 \%)$ showed normal BAEPs and abnormal SSEPs, and the remaining 33 patients (16.5\%) abnormal BAEPs and normal SSEPs. In the Table 3 the differences in normal/abnormal findings in CM subtypes with and without syringomyelia are presented. As expected, normal BAEPs and abnormal SSEPs were more frequent in patients with syringomyelia $\left(\chi^{2}=6.43, \mathrm{p}=0.011\right)$.

\section{BAEPs}

Of the whole cohort of 200 patients, 77 (38.5\%) had BAEP abnormalities (Table 3). Disturbances were predominantly observed at the retrocochlear level; the most common finding was prolongation of the I-V IPL and latency of the wave V (31.0\%) without differences in IPLs I-III and/ or III-V (Fig. 2). A cochlear auditory disturbance, defined by absence or prolonged latency of wave I, was found in only 7 patients $(3.5 \%)$. Of the 46 patients in whom CM was discovered incidentally and were asymptomatic, 18 (39.1\%) presented with abnormal BAEPs at a retrocochlear level. Of all the variables introduced in the logistic regression (age, sex, lower cranial nerve dysfunction, and all the described morphometric measurements) only age (OR 1.03, 95\% CI 1.00-1.06), the degree of tonsillar herniation (OR $1.08,95 \%$ CI 1.01-1.16), and lower cranial nerve dysfunction (OR 3.99, 95\% CI 1.29-14.01) had a statistically significant influence in predicting abnormal BAEPs (Table 4).

\section{SSEPS}

SSEPs were altered in 87 patients (43.5\%). Abnormal PTN SSEPs were found in $37 \%$ of patients, and the most common finding was the prolongation of N22-P37 IPL (33.0\%). Abnormal MN SSEPs were found in $22.5 \%$ of patients and the most common finding was the prolongation of N13-N20 IPL (13.0\%). Certain patients also presented with an abnormal cervical potential, either N13 or $\mathrm{N} 28$, with an altered cortical potential. No patient showed alteration of the peripheral potentials. Seventeen patients showed simultaneous PTN SSEP and MN SSEP alterations. Of all the variables introduced in the logistic regression, only age (OR $1.07,95 \%$ CI 1.04-1.10) and the degree of tonsillar herniation (OR 1.11, 95\% CI 1.04-1.19) had a 
TABLE 1. Summary of the clinical findings and associated pathology in $\mathrm{CM}^{*}$

\begin{tabular}{|c|c|c|c|c|}
\hline Variable & $\mathrm{CM}-0$ & $\mathrm{CM}-1$ & CM-1.5 & Total Cohort \\
\hline No. of patients & 14 & 137 & 49 & 200 \\
\hline Mean age $\pm S D$ (yrs) & $42.6 \pm 14.2$ & $41.8 \pm 12.8$ & $41.7 \pm 15.1$ & $41.9 \pm 13.4$ \\
\hline Asymptomatic & $4(28.6)$ & $33(24.1)$ & $9(18.4)$ & $46(23.0)$ \\
\hline Median age of symptom onset in yrs (range) & $39.0(14-65)$ & $34.0(10-61)$ & $34.0(4-65)$ & $34.0(4-65)$ \\
\hline Hydrocephalus & $5(35.7)$ & $18(13.1)$ & $13(26.5)$ & $36(18.0)$ \\
\hline Syringomyelia† & $9(64.3)$ & $70(51.1)$ & $17(34.7)$ & $96(48.0)$ \\
\hline Basilar invagination & $0(0.0)$ & $17(12.4)$ & $4(8.2)$ & $21(10.5)$ \\
\hline Platybasiał & $0(0.0)$ & $1(0.7)$ & $1(2.0)$ & $2(1.0)$ \\
\hline Surgery & $4(28.6)$ & $68(49.6)$ & $32(65.3)$ & $104(52.0)$ \\
\hline \multicolumn{5}{|l|}{ Symptoms } \\
\hline Headaches & $8(57.1)$ & $96(70.1)$ & $38(77.6)$ & $141(70.5)$ \\
\hline Cough headache§ & $2(14.3)$ & $56(40.9)$ & $26(53.1)$ & $84(42.0)$ \\
\hline Occipital neck & $5(35.7)$ & $66(48.2)$ & $31(63.3)$ & $102(51.0)$ \\
\hline Holocranial & $1(7.1)$ & $14(10.2)$ & $3(6.1)$ & $18(9.0)$ \\
\hline Other localizations & $2(14.3)$ & $12(8.8)$ & $4(8.2)$ & $18(9.0)$ \\
\hline Dizziness & $4(28.6)$ & $45(32.8)$ & $16(32.7)$ & $65(32.5)$ \\
\hline Sensory loss & $2(14.3)$ & $35(25.5)$ & $8(16.3)$ & $45(22.5)$ \\
\hline Anxiety & $3(21.4)$ & $35(25.5)$ & $7(14.3)$ & $45(22.5)$ \\
\hline Dysphagia & $6(42.9)$ & $27(19.7)$ & $11(22.4)$ & $44(22.0)$ \\
\hline \multicolumn{5}{|l|}{ Neurological examination } \\
\hline Abnormal & $7(50.0)$ & $76(55.5)$ & $26(53.1)$ & $109(54.5)$ \\
\hline Thermalgesic disturbances & $4(28.6)$ & $42(30.7)$ & $11(22.4)$ & $57(28.5)$ \\
\hline Hyporeflexia & $4(28.6)$ & $33(24.1)$ & $6(12.2)$ & $43(21.5)$ \\
\hline Hyperreflexia & $3(21.4)$ & $25(18.2)$ & $10(20.4)$ & $38(19.0)$ \\
\hline Motor deficit (paresis) & $2(14.3)$ & $26(19.0)$ & $4(8.2)$ & $32(16.0)$ \\
\hline Lower cranial nerve palsies & $1(7.1)$ & $12(8.8)$ & $5(10.2)$ & $18(9.0)$ \\
\hline Kyphoscoliosis & $1(7.1)$ & $15(10.9)$ & $3(6.1)$ & $19(9.5)$ \\
\hline Nystagmus & $3(21.4)$ & $10(7.3)$ & $3(6.1)$ & $16(8.0)$ \\
\hline Babinski sign & $1(7.1)$ & $11(8.0)$ & $3(6.1)$ & $15(7.5)$ \\
\hline Clonus & $2(14.3)$ & $4(2.9)$ & $1(2.0)$ & $7(3.5)$ \\
\hline Amyotrophy & $0(0.0)$ & $7(5.1)$ & $0(0.0)$ & $7(3.5)$ \\
\hline Proprioceptive dysfunction & $0(0.0)$ & $4(2.9)$ & $1(2.0)$ & $5(2.5)$ \\
\hline \multicolumn{5}{|c|}{ 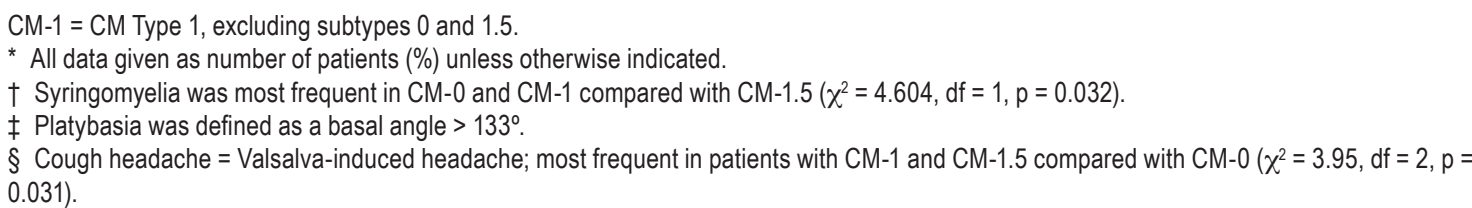 } \\
\hline
\end{tabular}

statistically significant influence in predicting abnormal SSEPs (Table 4).

\section{EPs in Asymptomatic Patients}

Asymptomatic patients or patients in whom CM-1 was discovered incidentally usually came to the Department of Neurosurgery of our hospital after being referred by other specialists after an incidental diagnosis in the study of other pathologies (headaches, whiplash injury, epilepsy, etc.) or after their diagnosis was made in the study of immediate family members of patients with CM. Of the 46 patients in whom $\mathrm{CM}$ was discovered incidentally and were asymptomatic, 23 (50\%) had abnormal EPs: 9 (19.6\%) pre- sented abnormal both BAEPs and SSEPs, 5 (10.9\%) normal BAEPs and abnormal SSEPs, and 9 (19.6\%) abnormal BAEPs and normal SSEPs. No relevant differences in percentages between symptomatic and asymptomatic patient groups, or between groups with or without syringomyelia, were found (Fig. 3).

\section{Discussion}

In this study we present a large cohort of patients with classic CM-1 in which we systematically studied EPs. In addition, we included an analysis of the clinical symptoms and the neuroradiological findings observed in the dif- 


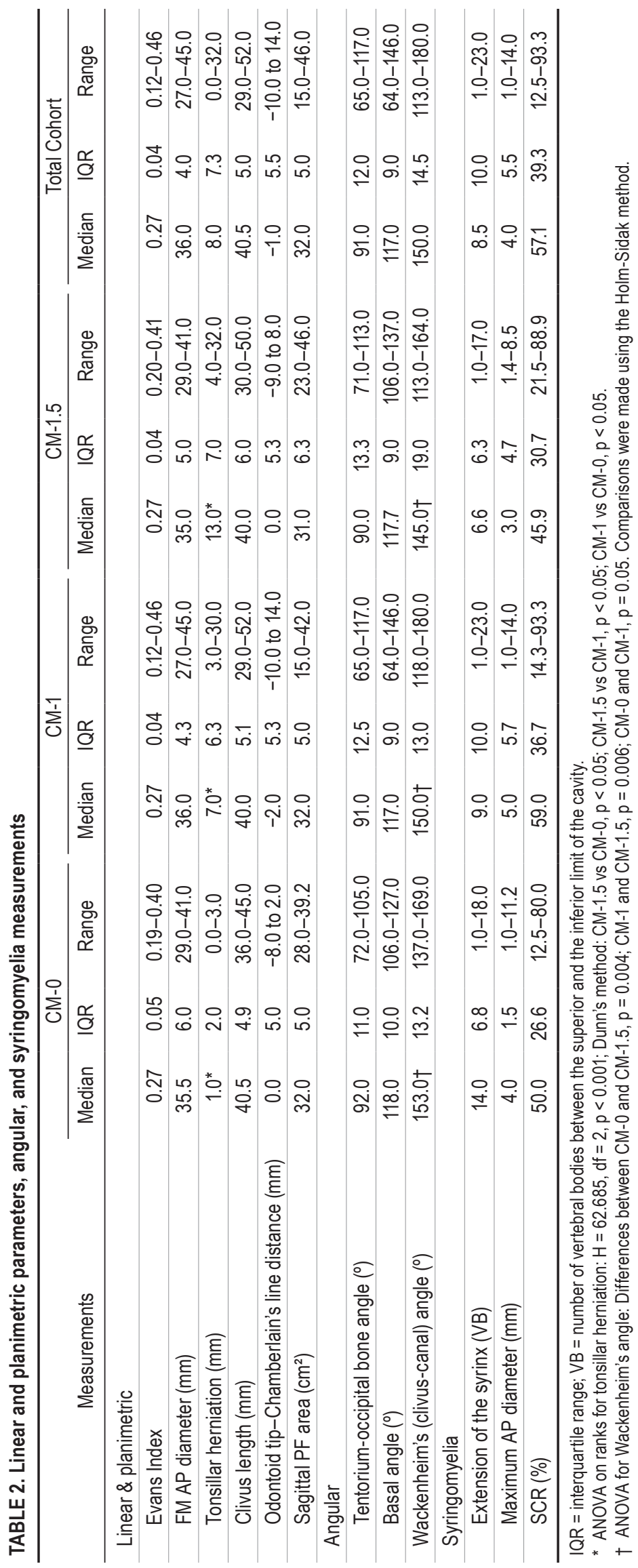


TABLE 3. Evoked potential findings in the different variants of $\mathrm{CM}^{*}$

\begin{tabular}{|c|c|c|c|c|c|c|c|c|}
\hline \multirow[b]{2}{*}{ EPs } & \multicolumn{2}{|c|}{$\mathrm{CM}-0$} & \multicolumn{2}{|c|}{$\mathrm{CM}-1$} & \multicolumn{2}{|c|}{ CM-1.5 } & \multicolumn{2}{|c|}{ Total Cohort } \\
\hline & $\begin{array}{c}\text { Yes } \\
(n=9)\end{array}$ & $\begin{array}{c}\text { No } \\
(n=5)\end{array}$ & $\begin{array}{c}\text { Yes } \\
(n=70)\end{array}$ & $\begin{array}{c}\text { No } \\
(n=67)\end{array}$ & $\begin{array}{c}\text { Yes } \\
(n=17)\end{array}$ & $\begin{array}{c}\text { No } \\
(n=32)\end{array}$ & $\begin{array}{c}\text { Yes } \\
(n=96)\end{array}$ & $\begin{array}{c}\text { No } \\
(n=104)\end{array}$ \\
\hline Normal BAEPs/SSEPs (\%) & $3(33.3)$ & $3(60.0)$ & $24(34.3)$ & $32(47.8)$ & $7(41.2)$ & $11(34.4)$ & $34(35.4)$ & $46(44.2)$ \\
\hline Abnormal BAEPs/SSEPs (\%) & $2(22.2)$ & $2(40.0)$ & $16(22.9)$ & $10(14.9)$ & $4(23.5)$ & $10(31.3)$ & $22(22.9)$ & $22(21.2)$ \\
\hline Normal BAEPs \& abnormal SSEPs $(\%) \dagger$ & $4(44.4)$ & $0(0.0)$ & $20(28.6)$ & $12(17.9)$ & $4(23.5)$ & $3(9.4)$ & $28(29.2)$ & $15(14.4)$ \\
\hline Abnormal BAEPs \& normal SSEPs (\%) & $0(0.0)$ & $0(0.0)$ & $10(14.3)$ & $13(19.4)$ & $2(11.8)$ & $8(25.0)$ & $12(12.5)$ & $21(20.2)$ \\
\hline
\end{tabular}

* Yes/no refers to the presence/absence of syringomyelia.

$\dagger$ Normal BAEPs and abnormal SSEPs were more frequent in patients with syringomyelia $\left(\chi^{2}=6.43, d f=1, p=0.011\right)$.

ferent subtypes of CM-1 subclassified by Tubbs et al. ${ }^{39,41}$ This new terminology, incorporated into the neurosurgical literature in the last decade, has not yet gained wide acceptance. However, the main advantage of this categorization is that it allows for better stratification of the different groups of patients traditionally included within classic CM-1. In our study, we used the 3-mm cutoff to define patients with $\mathrm{CM}-0$ instead of the 5-mm cutoff proposed by Tubbs et al. ${ }^{40}$ This criterion has also been used by other authors. ${ }^{38}$ Our main reason for changing the cutoff was that the degree of tonsillar herniation is not related to the development of syringomyelia. In addition, classifying CM-1 in patients with at least $5 \mathrm{~mm}$ of tonsillar herniation and CM-0 in patients without any hindbrain herniation-as originally proposed-renders many patients with 2-5 mm tonsillar herniation unclassifiable. In our cohort, 42 patients presented with tonsillar herniation between 2 and $5 \mathrm{~mm}$, and half of the patients presented a syrinx of variable extension. In the last published version of the classification proposed by Tubbs et al., CM- 0 was redefined as patients who "... do not have caudal displacement of the cerebellar tonsils beyond a point that could be considered pathologic $(<5 \mathrm{~mm}),{ }^{, 40}$ therefore assuming that a certain degree of tonsillar herniation should be accepted within the CM- 0 category. What is a pathological or "significant" herniation is still a matter of debate and has been biased by the MRI literature and the methodology used to define the range of reference. However, it is important to note that the 3-5 mm threshold in a T1-weighted midsagittal MR image is an arbitrary threshold and that the $5 \mathrm{~mm}$ cutoff - the most frequently used-exceeds the $3 \mathrm{~mm}$ cutoff proposed initially by Barkovich et al. ${ }^{4}$ In addition, the general acceptance that many patients with a crowded PF and no hindbrain herniation should be considered within the CM spectrum makes it reasonable to include "moderate" tonsillar herniation in the CM-1 category.

\section{Clinical Symptoms in the CM Subgroups}

The associated pathologies and clinical findings found in our entire cohort did not significantly differ from what has been reported in the literature for classic CM$1 .{ }^{26,28,29,39,41} \mathrm{CM}-0$ was found in $7.0 \%$ of our cohort. Our study supports the findings already described by other authors that patients with minimal tonsillar ectopia can present with severe neurological symptoms and associ-

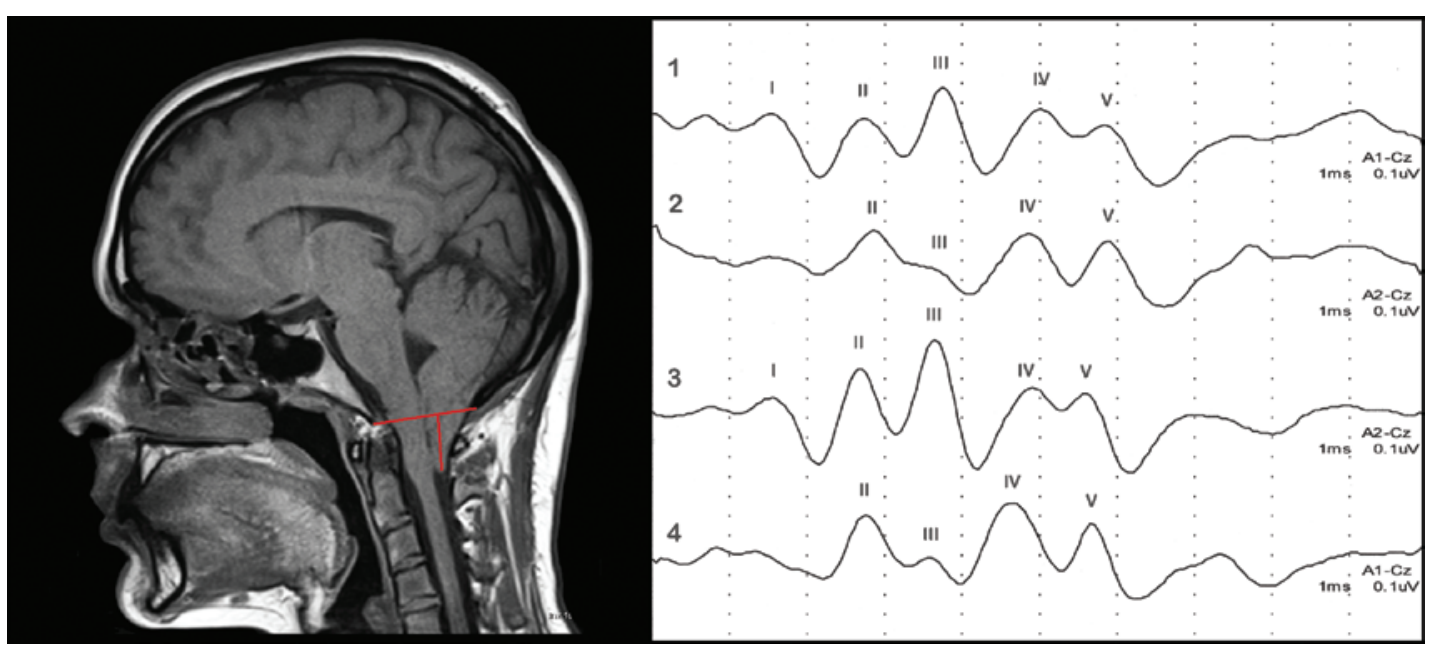

FIG. 2. BAEPs in a 26-year-old woman with CM-1.5. The sagittal midline T1-weighted MR image (left) shows a 20-mm tonsillar descent below the FM. Patient symptoms include headaches in an occipitonuchal location, exacerbated with Valsalva maneuvers. The graph (right) shows responses obtained from stimulation of the left ear (channels 1 and 2) and responses obtained from stimulation of the right ear (channels 3 and 4). BAEPs show an asymmetrical IPL I-V, longer in the left (4.29 msec) than in the right ear $(3.98 \mathrm{msec})$. Figure is available in color online only. 
TABLE 4. Logistic regression to predict the probability of an abnormal value in BAEPs and SSEPs

\begin{tabular}{|c|c|c|c|c|c|}
\hline Variables & Coefficient & SE & $p$ Value & OR & $95 \% \mathrm{Cl}$ \\
\hline \multicolumn{6}{|l|}{ BAEPs } \\
\hline Age & 0.0294 & 0.013 & $0.025^{*}$ & 1.03 & $1.00-1.06$ \\
\hline Sex (male) & -0.5139 & 0.380 & 0.177 & 0.60 & $0.28-1.26$ \\
\hline Lower cranial nerve palsies $†$ & 1.3828 & 0.598 & $0.021^{*}$ & 3.99 & $1.29-14.01$ \\
\hline $\mathrm{CM}-1$ & -0.2352 & 0.707 & 0.739 & 0.79 & $0.21-3.49$ \\
\hline CM-1.5 & -0.0728 & 0.835 & 0.931 & 0.93 & $0.19-5.11$ \\
\hline Syringomyelia & -0.4519 & 0.338 & 0.181 & 0.64 & $0.32-1.23$ \\
\hline Tonsillar herniation & 0.0773 & 0.033 & $0.020^{*}$ & 1.08 & $1.01-1.16$ \\
\hline Basal angle & 0.0075 & 0.022 & 0.737 & 1.01 & $0.97-1.06$ \\
\hline Wackenheim angle & -0.0028 & 0.016 & 0.862 & 1.00 & $0.97-1.03$ \\
\hline Clivus length & -0.0141 & 0.043 & 0.743 & 0.99 & $0.91-1.07$ \\
\hline FM diameter & -0.0002 & 0.058 & 0.997 & 1.00 & $0.89-1.12$ \\
\hline PF area & 0.0117 & 0.049 & 0.811 & 1.01 & $0.92-1.11$ \\
\hline \multicolumn{6}{|l|}{ SSEPS } \\
\hline Age & 0.0695 & 0.015 & $<0.001^{*}$ & 1.07 & $1.04-1.10$ \\
\hline Sex (male) & -0.7574 & 0.400 & 0.058 & 0.47 & $0.21-1.02$ \\
\hline Hyporeflexia & 0.2234 & 0.445 & 0.617 & 1.25 & $0.52-3.01$ \\
\hline Thermalgesic disturbances & 0.0808 & 0.426 & 0.850 & 1.08 & $0.46-2.49$ \\
\hline $\mathrm{CM}-1$ & -1.0746 & 0.746 & 0.150 & 0.34 & $0.08-0.46$ \\
\hline CM-1.5 & -1.2424 & 0.877 & 0.157 & 0.29 & $0.05-1.58$ \\
\hline Tonsillar herniation & 0.1023 & 0.034 & $0.003^{*}$ & 1.11 & $1.04-1.19$ \\
\hline Basal angle & -0.0038 & 0.022 & 0.862 & 1.00 & $0.95-1.04$ \\
\hline Wackenheim angle & 0.0160 & 0.017 & 0.351 & 1.02 & $0.98-1.05$ \\
\hline Clivus length & -0.0097 & 0.045 & 0.830 & 0.99 & $0.91-1.08$ \\
\hline PF area & -0.0235 & 0.053 & 0.667 & 0.98 & $0.88-1.08$ \\
\hline FM diameter & 0.0011 & 0.061 & 0.986 & 1.00 & $0.89-1.13$ \\
\hline Syringomyelia & -0.0212 & 0.690 & 0.975 & 0.98 & $0.25-3.75$ \\
\hline Syrinx extension & 0.0591 & 0.044 & 0.180 & 1.06 & $0.97-1.16$ \\
\hline SCR & 0.0003 & 0.011 & 0.978 & 1.00 & $0.98-1.02$ \\
\hline
\end{tabular}

ated syringomyelia. ${ }^{19}$ These patients were more frequently symptomatic because of motor weakness and sensory disturbance induced by the syringomyelia that was more frequent than in the other two groups.

With regard to symptoms, only Valsalva maneuver-induced headache was more frequent in patients with CM-1 and CM-1.5 compared with CM-0 $\left(\chi^{2}=3.95, p=0.031\right.$; Table 1), suggesting a possible relationship of this symptom with a greater degree of tonsillar descent. Dizziness and dysphagia, common symptoms in $\mathrm{CM}$, were not significantly higher in patients with CM-1.5. Our findings are consistent with that of Tubbs et al. who concluded from their series of 22 children and young adults that no single sign or symptom was predominant in patients with CM$1.5 .^{41}$ In our cohort, syringomyelia was more frequent in patients with CM-0 and CM-1 than in those with CM-1.5. The increased finding of syringomyelia in patients with CM-0 may represent a bias toward more patients in this category being diagnosed because of more severe neuro- logical symptoms related to the syrinx (Table 1). We cannot explain why patients with more severe herniation of the hindbrain presented with fewer syrinxes than patients in the CM-1 group, a finding that was not observed in other series. ${ }^{41}$

\section{Neuroradiological and Morphometric Findings}

The entire cohort presented significant differences in some morphometric measurements compared with a control group that we published elsewhere..$^{42}$ In summary, our cohort presented radiological signs of an underdeveloped PF with a significant shorter clivus length, reduced sagittal PF area, and a more closed tentorium-occipital bone angle. These findings are in agreement with previous morphometric studies that have shown an undergrowth of the $\mathrm{PF}$ as the primary pathogenic factor both in adults and in pediatric patients with CM. ${ }^{3,28,42,44}$ These findings also support theories introduced by Marin-Padilla-reproduced experimentally in rodents - that stated that the reduced $\mathrm{PF}$ 


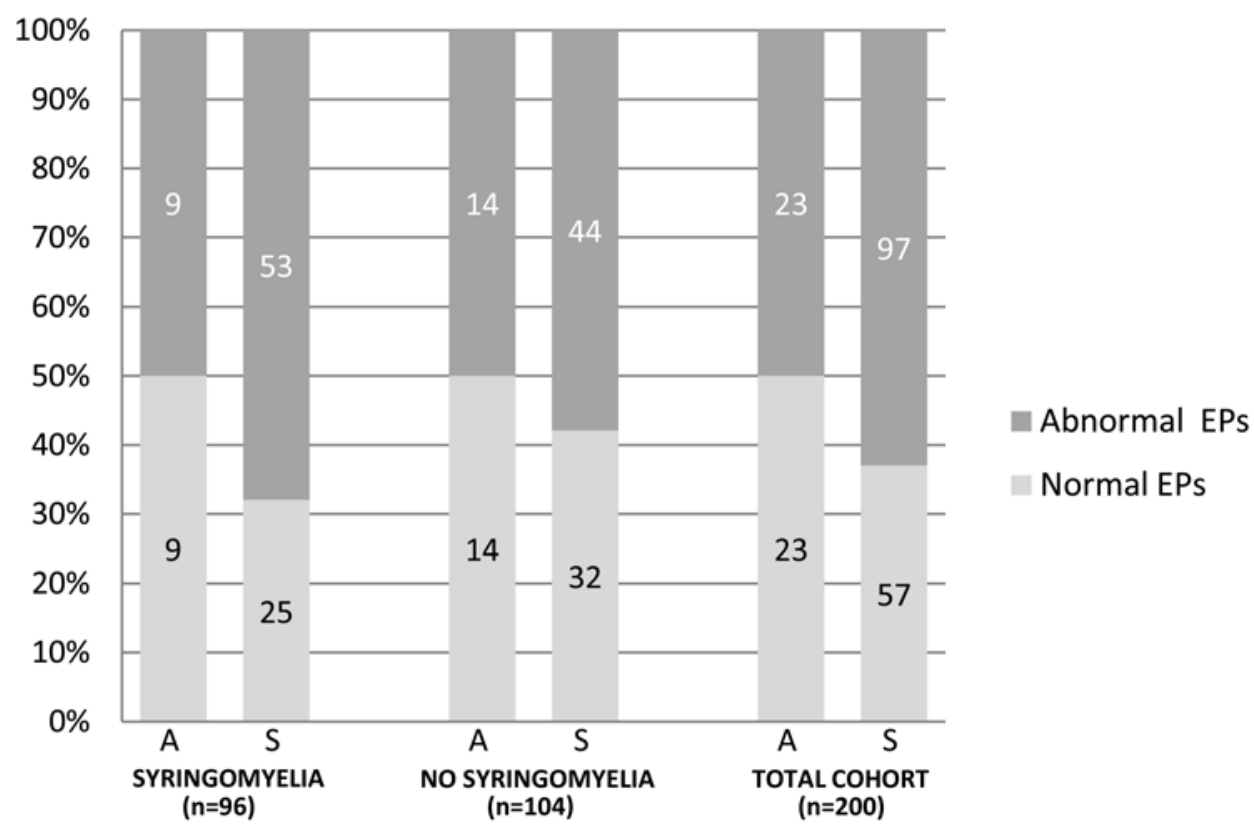

FIG. 3. Stacked bar showing the percentages of abnormal and normal EPs in asymptomatic (A) and symptomatic (S) patients. Both groups with and without syringomyelia, as well in the total cohort, are shown. The number of patients is shown inside the stacked bars.

volume found in patients with $\mathrm{CM}$ was the consequence of a primary paraaxial mesodermal anomaly. ${ }^{24,25}$ When we analyzed the morphometric findings in our 3 subgroups, we did not find any finding that was significantly different except for tonsillar herniation. On average, patients with CM-1.5 presented with a much more significant degree of tonsillar ectopia than patients with CM-1. In part, this difference may be justified by the intrinsic bias introduced by the classification. However, the surrogate indices of a small PF (area on the sagittal MRI slice, clivus length, or the tentorium-occipital angle) were not significantly different among the groups, suggesting that the degree of PF hypoplasia was homogeneous across all groups, as previously noted by other authors. ${ }^{26,38}$ Our findings suggest that other unknown factors besides the degree of PF hypoplasia are determinants of hindbrain herniation.

Whether CM-0, CM-1, or CM-1.5 are different phenotypic expressions of the same malformation or just different stages of the same disease is still unknown and necessitates additional studies with longer follow-up durations. Recent studies have shown that CM-0 and CM-1 groups share similar clinical and radiological features, and most importantly, that both types of CM have been found in members within the same family. ${ }^{26}$ This fact suggests that this disorder may share an underlying genetic disorder and that epigenetic factors may play an important role in the final phenotype. ${ }^{26}$ Anecdotal reports with a long followup have revealed that CM-1 can evolve into more severe forms of hindbrain herniation. Kim et al. described a single case of an adolescent with an incidentally diagnosed CM-1 that showed progressive downward herniation of the tonsils and the obex and who developed syringomyelia over 9 years of follow-up. This study suggests the potentiality for progression from one CM category to another. ${ }^{21}$

\section{EP Findings}

To our knowledge, the first published report on EP findings in CM-1 was conducted by Anderson et al. in $1986 .{ }^{2}$ Since then, only a few articles on the subject have been published. Most of these studies have been retrospective studies with a limited number of patients and diverse patient populations. The majority of these studies focused on SSEPs in patients with syringomyelia..$^{2,20,32,35,45}$ Restuccia and Mauguière ${ }^{35}$ observed findings consistent with those reported by Anderson et al.; Restuccia and Mauguière described the most frequent disturbance as an alteration or absence of the cervical potential and an increased N13N20 IPL. Median nerve SSEP cervical potential alterations in our cohort were not as frequent $(6.5 \%)$ as those found in other studies, which is likely due to the fact that the study groups are not entirely comparable. Only $48 \%$ of our patients presented with syringomyelia, compared with $100 \%$ in the studies by Anderson et al. and Restuccia and Mauguiere. ${ }^{2,35}$

One hundred and twenty patients $(60 \%)$ showed alterations in EP recordings with some differences in the percentages among the 3 subtypes (CM- $0, \mathrm{CM}-1$, and CM-1.5) and between groups with and without syringomyelia (Table 3). Eight of the 14 patients with CM-0 had abnormal EPs; 2 patients without syringomyelia exhibited abnormal BAEPs and SSEPs simultaneously. One of these patients had typical symptoms and signs, but the second patient only presented with an occipitonuchal headache and a normal neurological examination. These BAEP and SSEP findings revealed an objective dysfunction in this patient, the severity of which could not have been deduced by her nonspecific complaints nor by the severity of her malformation. A larger percentage of patients with CM1.5 presented with abnormal BAEPs even in patients with- 
out syringomyelia, but all of the patients were clinically symptomatic (Fig. 2).

BAEPs evaluate auditory pathway functioning along the proximal intracranial portion of the auditory nerve and cochlear nucleus to the inferior colliculus of the midbrain. Forty percent of the patients in our cohort exhibited both normal BAEPs and SSEPs, highlighting the fact that on average $35.4 \%$ of the patients with syringomyelia had normal EPs (41.2\% in the CM-1.5 group; Table 3). BAEPs were abnormal in 77 patients (38.5\%). Excluding our preliminary report published elsewhere, ${ }^{31}$ to our knowledge, only 1 other study with more than 20 patients has described the findings of BAEPs in patients with classic CM-1. ${ }^{17}$ Henriques Filho and Pratesi reported that the most frequent abnormality found in BAEPs in classic CM-1 was on a cochlear or auditory peripheral level. ${ }^{17}$ Our study did not confirm these findings. Although peripheral or cochlear disturbances were found in a few patients, the incidence of these disturbances was similar to the BAEP findings in the general population and thus was most likely unrelated to the malformation and could be attributed to age-related sensorineural hearing loss.

Of all the variables introduced in the logistic regression, only age, the degree of tonsillar herniation, and lower cranial nerve dysfunction had a statistically significant influence in predicting abnormal BAEPs (Table 4). This finding can be easily explained by the fact that the more severe distortion of the brainstem structures induced more BAEP abnormalities and therefore, as expected, patients with lower cranial nerve dysfunction presented with a higher frequency of abnormal BAEPs.

SSEPs evaluate the dorsal column-medial lemniscus pathway including the spinal cord and brainstem levels. The lemniscal pathways are typically affected in patients with severe or advanced syringomyelia. Syringomyelia was most frequent in patients with CM-0 (64.3\%) and CM-1 (51.1\%) compared with those with CM-1.5 (34.7\%; Table 1). In our series, consistent with other studies, most of the patients with a thermalgesic disturbance-the most frequent neurological finding in patients with syringomyelia-also exhibited altered SSEPs. ${ }^{2,35}$ Of all the variables introduced in the logistic regression model, only age and the degree of tonsillar herniation were statistically significant at predicting abnormal SSEPs (Table 4). These findings indicate a greater probability of finding abnormal SSEPs in patients who are older and have a greater degree of tonsillar descent.

An important finding in our series was that in asymptomatic patients in whom CM had been discovered incidentally, 50\% presented with at least 1 abnormal EP (Fig. 3). BAEPs were abnormal in $39.1 \%$ of asymptomatic patients on a retrocochlear level. SSEPs were also abnormal in $30.4 \%$ patients in whom CM had been found incidentally. These findings clarify that EPs might be useful for informing the clinician and the patient about the existence of objective neurophysiological abnormalities. In this scenario, the progression of the disease would be highly probable, but because of the design of our study we could not infer that abnormalities in any EPs were predictive of a higher likelihood of disease progression. Only additional studies in cohorts of oligosymptomatic patients with long-term follow-up may be able to answer this clinical question. An example of how neurophysiological studies have changed surgical indications is the knowledge that sleep apnea/hypopnea syndromes are frequently detected in asymptomatic patients. CM in all of its forms may produce neuronal dysfunctions of the brainstem, cerebellum, cranial nerves, medulla, and upper spinal cord. The respiratory center and its afferent/efferent components are localized at the cervicomedullary junction and may also be altered by the disease..$^{10}$ The findings of a sleep apnea/hypopnea syndrome in cases in which CM has been incidentally found have dramatically changed the surgical indications at our institution. ${ }^{16}$

\section{Conclusions}

In this study, 120 patients (60\%) with $\mathrm{CM}$ showed alterations in their EP recordings. Of the 46 asymptomatic patients in whom CM had been discovered incidentally, 23 (50\%) had abnormal EPs. Whether EPs are useful in the workup of CM needs to be put into a clinical context. In clearly symptomatic patients or in patients in whom syringomyelia induces severe symptoms (e.g., sensory loss and motor weakness) because of its size and location in the neuroaxis, our findings suggest that neither BAEPs nor SSEPs add any clinically relevant information, nor are they helpful in establishing which patients should undergo surgical treatment. Therefore, except for clinical research or very carefully selected patients in whom the progression of the disease needs to be confirmed, classic EPs do not need to be included in the routine workup of CM. One explanation for these findings is that BAEPs detect subclinical lesions that can occur in both symptomatic patients and patients in whom CM was incidentally found; these lesions are more related to the degree of tonsillar descent and to the severity of the CM malformation. In addition, SSEPs are more useful at defining the damage that the spinal cord has already suffered and therefore helping the clinician to evaluate the options of reversibility after surgery. SSEPs are also useful in the follow-up of patients for whom syringomyelic symptoms have apparently stabilized and who require follow-up to define further subclinical progression.

EPs clearly play an important role in clinically asymptomatic/oligosymptomatic patients. The management of asymptomatic patients with $\mathrm{CM}$ is an important medical problem, and this topic remains a source of debate. This situation persists because such patients are currently being diagnosed more frequently because of the widespread availability of MRI techniques. Additionally, the potentiality for progression of the disease at a young age pushes many clinicians to recommend early surgical treatment. Although data concerning the management and clinical progression of asymptomatic patients are still limited and further research with long-term follow-up are required, EPs could help in establishing objective evidence of subclinical dysfunctions that may indicate a need for surgical intervention.

\section{Acknowledgments}

The Neurotraumatology and Neurosurgery Research Unit is supported by a grant from the Departament d'Universitats, 
Recerca i Societat de la Informació de la Generalitat de Catalunya (SGR 2014-844). We would like to thank the personnel of the neurophysiology department, especially nurses M.E. Bas, M.A. Planelles, and M.V. Soriano for their help and technical assistance in conducting EP recordings.

\section{References}

1. American Clinical Neurophysiology Society: Guideline 9A: Guidelines on evoked potentials. J Clin Neurophysiol 23:125-137, 2006

2. Anderson NE, Frith RW, Synek VM: Somatosensory evoked potentials in syringomyelia. J Neurol Neurosurg Psychiatry 49:1407-1410, 1986

3. Aydin S, Hanimoglu H, Tanriverdi T, Yentur E, Kaynar MY: Chiari type I malformations in adults: a morphometric analysis of the posterior cranial fossa. Surg Neurol 64:237-241, 2005

4. Barkovich AJ, Wippold FJ, Sherman JL, Citrin CM: Significance of cerebellar tonsillar position on MR. AJNR Am J Neuroradiol 7:795-799, 1986

5. Batista UC, Joaquim AF, Fernandes YB, Mathias RN, Ghizoni E, Tedeschi H: Computed tomography evaluation of the normal craniocervical junction craniometry in 100 asymptomatic patients. Neurosurg Focus 38(4):E5, 2015

6. Bogdanov EI, Heiss JD, Mendelevich EG, Mikhaylov IM, Haass A: Clinical and neuroimaging features of "idiopathic" syringomyelia. Neurology 62:791-794, 2004

7. Botelho RV, Bittencourt LR, Rotta JM, Tufik S: A prospective controlled study of sleep respiratory events in patients with craniovertebral junction malformation. J Neurosurg 99:1004-1009, 2003

8. Botelho RV, Ferreira ED: Angular craniometry in craniocervical junction malformation. Neurosurg Rev 36:603-610, 2013

9. Boyles AL, Enterline DS, Hammock PH, Siegel DG, Slifer SH, Mehltretter L, et al: Phenotypic definition of Chiari type I malformation coupled with high-density SNP genome screen shows significant evidence for linkage to regions on chromosomes 9 and 15. Am J Med Genet A 140:2776-2785, 2006

10. Caruana-Montaldo B, Gleeson K, Zwillich CW: The control of breathing in clinical practice. Chest 117:205-225, 2000

11. Chiari H: Concerning alterations in the cerebellum resulting from cerebral hydrocephalus (English translation). Pediatr Neurosci 13:3-8, 1987

12. Chiari H: Über Veränderungen des Kleinhirns Infolge von Hydrocephalie des Grosshirns. Dtsch Med Wochenschr 17:1172-1175, 1891

13. Chiari H: Über Veränderungen des Kleinhirns, des Pons und der Medulla Oblongata in Folge von Congenitaler Hydrocephalie. Denkschr Akad Wiss Wien 63:71-116, 1896

14. Cruccu G, Aminoff MJ, Curio G, Guerit JM, Kakigi R, Mauguiere F, et al: Recommendations for the clinical use of somatosensory-evoked potentials. Clin Neurophysiol 119:1705-1719, 2008

15. Evans JWA: An encephalographic ratio for estimating ventricular enlargement and cerebral atrophy. Arch Neurol Psychiatry 47:931-937, 1942

16. Ferre-Maso A, Poca MA, de la Calzada MD, Solana E, Romero-Tomas O, Sahuquillo J: Sleep disturbance: a forgotten syndrome in patients with Chiari I malformation. Neurologia 29:294-304, 2014

17. Henriques Filho PS, Pratesi R: Abnormalities in auditory evoked potentials of 75 patients with Arnold-Chiari malformations types I and II. Arq Neuropsiquiatr 64:619-623, 2006

18. Hosmer DW, Lemeshow S, Sturdivant RX: Applied Logistic Regression, ed 3. Hoboken, NJ: Wiley, 2013

19. Iskandar BJ, Hedlund GL, Grabb PA, Oakes WJ: The resolu- tion of syringohydromyelia without hindbrain herniation after posterior fossa decompression. J Neurosurg 89:212-216, 1998

20. Jabbari B, Geyer C, Gunderson C, Chu A, Brophy J, McBurney JW, et al: Somatosensory evoked potentials and magnetic resonance imaging in syringomyelia. Electroencephalogr Clin Neurophysiol 77:277-285, 1990

21. Kim IK, Wang KC, Kim IO, Cho BK: Chiari 1.5 malformation: an advanced form of Chiari I malformation. J Korean Neurosurg Soc 48:375-379, 2010

22. Koenigsberg RA, Vakil N, Hong TA, Htaik T, Faerber E, Maiorano T, et al: Evaluation of platybasia with MR imaging. AJNR Am J Neuroradiol 26:89-92, 2005

23. Kyoshima K, Kuroyanagi T, Oya F, Kamijo Y, El-Noamany H, Kobayashi S: Syringomyelia without hindbrain herniation: tight cisterna magna. Report of four cases and a review of the literature. J Neurosurg 96 (2 Suppl):239-249, 2002

24. Marín-Padilla M: Notochordal alterations in axial skeletalneural dysraphic disorders. Virchows Arch A Pathol Anat Histopathol 422:97-98, 1993

25. Marín-Padilla M, Marín-Padilla TM: Morphogenesis of experimentally induced Arnold-Chiari malformation. J Neurol Sci 50:29-55, 1981

26. Markunas CA, Tubbs RS, Moftakhar R, Ashley-Koch AE, Gregory SG, Oakes WJ, et al: Clinical, radiological, and genetic similarities between patients with Chiari Type I and Type 0 malformations. J Neurosurg Pediatr 9:372-378, 2012

27. Meadows J, Kraut M, Guarnieri M, Haroun RI, Carson BS: Asymptomatic Chiari Type I malformations identified on magnetic resonance imaging. J Neurosurg 92:920-926, 2000

28. Milhorat TH, Chou MW, Trinidad EM, Kula RW, Mandell $\mathrm{M}$, Wolpert C, et al: Chiari I malformation redefined: clinical and radiographic findings for 364 symptomatic patients. Neurosurgery 44:1005-1017, 1999

29. Milhorat TH, Nishikawa M, Kula RW, Dlugacz YD: Mechanisms of cerebellar tonsil herniation in patients with Chiari malformations as guide to clinical management. Acta Neurochir (Wien) 152:1117-1127, 2010

30. Moncho D, Poca MA, Minoves T, Ferré A, Rahnama K, Sahuquillo J: Brainstem auditory and somatosensory evoked potentials: a methodological study to evaluate the reproducibility of two devices. Physiol Meas 35:N51-N63, 2014 (Erratum in Physiol Meas 36:177, 2015)

31. Moncho D, Poca MA, Minoves T, Ferré A, Rahnama K, Sahuquillo J: Brainstem auditory and somatosensory evoked potentials in relation to clinical and neuroimaging findings in Chiari type 1 malformation. J Clin Neurophysiol 32:130138,2015

32. Moncho D, Poca MA, Minoves T, Ferré A, Rahnama K, Sahuquillo J: [Brainstem auditory evoked potentials and somatosensory evoked potentials in Chiari malformation.] Rev Neurol 56:623-634, 2013 (Sp)

33. Mortazavi MM, Tubbs RS, Brockerhoff MA, Loukas M, Oakes WJ: The first description of Chiari I malformation with intuitive correlation between tonsillar ectopia and syringomyelia. J Neurosurg Pediatr 7:257-260, 2011

34. Nuwer MR, Aminoff M, Desmedt J, Eisen AA, Goodin D, Matsuoka S, et al: IFCN recommended standards for short latency somatosensory evoked potentials. Report of an IFCN committee. Electroencephalogr Clin Neurophysiol 91:611,1994

35. Restuccia D, Mauguière F: The contribution of median nerve SEPs in the functional assessment of the cervical spinal cord in syringomyelia. A study of 24 patients. Brain 114 (Pt 1B):361-379, 1991

36. Sahuquillo J, Poca MA, Rovira A, Raspall G, Chasampi A: A new surgical technique for the treatment of Chiari I mal- 
formation and Chiari I/syringomyelia complex: preliminary results in patients, in Samii M (ed): Skull Base Surgery: Anatomy, Diagnosis, and Treatment. Basel: Karger, 1994, pp 1126-1129

37. Sahuquillo J, Rubio E, Poca MA, Rovira A, Rodriguez-Baeza A, Cervera C: Posterior fossa reconstruction: a surgical technique for the treatment of Chiari I malformation and Chiari I/syringomyelia complex-preliminary results and magnetic resonance imaging quantitative assessment of hindbrain migration. Neurosurgery 35:874-885, 1994

38. Sekula RF Jr, Jannetta PJ, Casey KF, Marchan EM, Sekula LK, McCrady CS: Dimensions of the posterior fossa in patients symptomatic for Chiari I malformation but without cerebellar tonsillar descent. Cerebrospinal Fluid Res 2:11, 2005

39. Tubbs RS, Elton S, Grabb P, Dockery SE, Bartolucci AA, Oakes WJ: Analysis of the posterior fossa in children with the Chiari 0 malformation. Neurosurgery 48:1050-1055, 2001

40. Tubbs RS, Griessenauer CJ, Oakes WJ: Chiari malformations, in Albright AL, Pollack IF, Adelson PD (eds): Principles and Practice of Pediatric Neurosugery, ed 3. New York: Thieme, 2014, pp 192-204

41. Tubbs RS, Iskandar BJ, Bartolucci AA, Oakes WJ: A critical analysis of the Chiari 1.5 malformation. J Neurosurg 101 (2 Suppl):179-183, 2004

42. Urbizu A, Poca MA, Vidal X, Rovira A, Sahuquillo J, Macaya A: MRI-based morphometric analysis of posterior cranial fossa in the diagnosis of Chiari malformation type I. J Neuroimaging 24:250-256, 2014

43. Urbizu A, Toma C, Poca MA, Sahuquillo J, Cuenca-León E, Cormand B, et al: Chiari malformation type I: a case-control association study of 58 developmental genes. PLoS One 8:e57241, 2013
44. Vega A, Quintana F, Berciano J: Basichondrocranium anomalies in adult Chiari type I malformation: a morphometric study. J Neurol Sci 99:137-145, 1990

45. Vidmer S, Sergio C, Veronica S, Flavia T, Silvia E, Sara B, et al: The neurophysiological balance in Chiari type 1 malformation (CM1), tethered cord and related syndromes. Neurol Sci 32 (3 Suppl 3):S311-S316, 2011

\section{Disclosures}

The authors report no conflict of interest concerning the materials or methods used in this study or the findings specified in this paper.

\section{Author Contributions}

Conception and design: Poca, Moncho, Minoves, Sahuquillo. Acquisition of data: Poca, Moncho, Cañas, Sahuquillo. Analysis and interpretation of data: Poca, Moncho, Minoves, Sahuquillo. Drafting the article: Poca, Moncho, Sahuquillo. Critically revising the article: all authors. Reviewed submitted version of manuscript: all authors. Approved the final version of the manuscript on behalf of all authors: Poca. Statistical analysis: Moncho, Sahuquillo. Administrative/technical/material support: Sahuquillo. Study supervision: Poca, Sahuquillo.

\section{Correspondence}

Maria A. Poca, Department of Neurosurgery, Vall d'Hebron University Hospital, Universitat Autònoma de Barcelona, Passeig Vall d'Hebron, 119-129, Barcelona 08035, Spain. email: pocama@neurotrauma.net. 